\title{
Bullying in Higher Education in Taiwan: The Taiwan Higher Education Faculty Survey (THEFS)
}

\author{
Christian Schafferer ${ }^{*}$ and Andrew Szanajda ${ }^{\dagger}$
}

Over the past several decades, educational systems in many parts of the world have undergone manifold changes that have significantly affected the work environment of educators. Among other negative impacts of the globalized reforms in higher education has been the increasing prevalence of workplace bullying. The purpose of this research note is to serve different purposes: (1) examine the causes behind the changing landscape of higher education; (2) discuss previous and current research on workplace bullying; (3) introduce the methodology of the Taiwan Higher Education Faculty Survey (THEFS); (4) outline its anticipated outcome.

\section{Global trends in higher education and consequences}

Higher or post-secondary education includes universities, colleges and junior colleges (Varghese, 2012). During the 1960s and 1970s, higher education expanded worldwide as a result of considerable governmental support. This boom ended in the 1980s when enrolment figures and the share of public resources allocated to higher education declined. As a consequence, members of the scholarly community shifted to other employment sectors or sought employment abroad while research facilities, the quality of teaching and academic standards declined considerably. Although this trend was observable worldwide, conditions in the developing world were the most greatly affected (Varghese, 2012: 45-46). In the late 1990s, there was a revitalization in the education sector that was caused by global changes involving three actors - the state, employers, and households (Varghese, 2012: 47). The most important change was the changing perception of the economic value of higher education in a globalized economic system. That is, research and education became acknowledged as key factors in securing industrial and technological competitiveness (Dobbins, Knill and Vögtle, 2011), which led to new initiatives and investments into the education sector.

The rise of higher education in the 1960s and 1970s and the subsequent decline in the 1980s are related to developments in the labor market. In the first decades after the Second World War, the public sector became the major employer of university graduates, and consequently higher education boomed as a result. In the 1980s however, employment patterns shifted away from the public to the private sector. As requirements differ significantly in both sectors, post-secondary education had to be diversified and extended into new disciplines. Consequently,

\footnotetext{
*Associate Professor, Department of International Trade, Overseas Chinese University, Taiwan (chris@ocu.edu.tw).

${ }^{\dagger}$ Associate Professor, Department of Applied English, Overseas Chinese University, Taiwan (andrew.szanajda@gmail.com).
} 
new degrees and certified courses offered incentives to invest in higher education to a much greater number of households than in previous decades. In addition, social demand for higher education was on the rise due to the growing number of secondary school graduates seeking further education (Varghese, 2012: 48). However, the public sector lacked financial and institutional capabilities to meet these growing demands. As a result, new ways of financing had to be found and the private sector became a promising alternative. Globalization and the knowledge economy later accelerated and intensified this transformation process (Kwiek, 2008). The revitalization of higher education drastically increased enrollment figures in countries belonging to all level of developments and geographical regions. Moreover, higher education in middle income countries could be categorized as "massified" and in most OECD countries, nearing universalization (Varghese, 2012: 48).

Over the last two decades, the role of the state changed fundamentally from a "provider of welfare benefits" to a "builder of markets" (Sbragia, 2000). In terms of education, the new paradigm \leG to the marketization and privatization of education. New concepts, such as New Public Management (Page, 2005) and the "entrepreneurial university" (Clark, 1998), have replaced global postwar patterns of university governance (Shattock, 2008). In the European context for example, the EU has envisaged a radical transformation of university governance in order to successfully implement its Lisbon Strategy for creating more jobs and growth. Under the new concept, universities are required to deliver services to society and the private sector, whereas governments are urged to shift from state control to accountability to society (Kwiek, 2008: 758). A further important aspect of the new governance model is quality control and striving for global competitiveness. University rankings and national programs of excellence have challenged the education landscape globally (Liu and Cheng, 2005). Other results of the revitalization of higher education include: (1) the commercialization of university know-how (Cook et al, 2008); (2) the emergence of the Triple Helix model of cooperation between government, the private sector and university (Etzkowitz and Leydesdorff, 2000); (3) the internationalization of universities (Altbach and Knight, 2007); (4) the future funding of higher education (Armbruster, 2008).

The new marketing-oriented approach also has its critics and shortcomings. Suzuki (1989), Readings (1996) and Ritzer (1996) were among the early scholars pointing at the potential risks of commercializing higher education and conceptualized such a process as the "prostitution of academia," which would lead to "fast food academic chain stores." More recent studies, such as Wilkesmann and Schmid (2012), show that New Public Management has produced a new breed of educators who are conditioned by entrepreneurial logic. There is concern among liberal scholars that this new corporate academic culture may endanger the traditional role of higher education in liberal democracies, which is to educate society for active and critical citizenship (Giroux, 2002). Moreover, the revitalization of higher education in developed societies has been accompanied by rising unemployment among university graduates, a dramatic increase in the cost of higher education, grade inflation, and growing doubt about the value of higher education (Barber et al, 2013). Scholars also draw attention to the negative social and political impact of the global quest for world-class universities in response to the intensifying competition in the higher education sector (Deem, Mok and Lucas, 2008). In addition, entrepreneurialism has worsened the working conditions of faculty members, have intensified intra-faculty competition and have created potential conflicts between management and academic personnel (Mainardes, Alves and Raposo, 2011). 


\section{Taiwan and higher education}

Higher education in Taiwan is comprised of (1) universities and colleges, offering undergraduate and graduate courses, and (2) junior colleges, awarding diplomas upon graduation. Institutions of higher education were first established in the early twentieth century when Taiwan was under Japanese occupation. The Japanese considered economic development as one of the most important pillars of colonial rule, and thus encouraged entrepreneurship and put great emphasis on education, especially on primary and vocational education to increase productivity (Phillips, 2003). However, higher education was mostly restricted to Japanese citizens and it was not before the early 1920s that a growing number of Taiwanese were allowed to enroll in commercial and agricultural colleges as well as the island's first universities and medical schools (Beasley, 1987: 147).

At the end of World War II, the United States, as the principal occupying power of Japanese territory, authorized the Chinese President Chiang Kai-shek to administer Taiwan. The expansion of higher education in postwar Taiwan began in the early 1960s as a result of industrialization and the rapid growth of secondary school education (Wang, 2003: 263). In 1964, a special committee in charge of manpower development was set up to project the demand for manpower in accordance with the government's planned economic growth rate and industrial structure. Until the mid-1980s, manpower projections determined the growth of higher education (Wang, 2003: 263). Government policies led to a boom in the higher education sector in the mid-1960s, with annual growth rates averaging 30 percent. The number of institutions then increased from 27 in 1960 to 92 in 1970, and student enrollment numbers quadrupled during the same time. Expansion mostly took place within the junior college sector in order to cultivate medium-level manpower that was required by industry and business (Wu, Chen and $\mathrm{Wu}, 1989: 126)$. Most of the newly established institutions were established and funded by the private sector (Wang, 2003: 262).

During the 1980s, the demand for higher education increased due to the changing political and social environment, arising from rapid economic growth, urbanization and rising living standards. Education could no longer be solely determined by manpower development plans, but had had to cater to the demands of a growing middle class and politically more active citizens (Wang, 2003: 265). In 1985, the government liberalized higher education by lifting previous restrictions on the establishment of institutions by the private sector (Yung, 2009: 8). Taiwan's higher education in the 1980s can be conceptualized as processes of privatization, decentralization, and "autonomisation" (Mok, 2003: 122). In other words, the state gave up its monopoly on higher education, moving away from the "state-control model" to the "state supervision model." Universities thus gained a greater degree of autonomy in terms of their management and functions (Mok, 2003: 122).

Since the early 1990s, Taiwan's higher education has followed globalization trends, which has led to higher education having become more greatly diversified and commercialized (Yung, 2009), and has shifted from elitism to mass education (Wang 2003). Taiwan has also joined efforts found worldwide in striving to establish world-class universities and has likewise followed the trend of internationalization (Deem, Mok and Lucas, 2008). However, Taiwanese higher education institutions have suffered from decreasing numbers of students in recent years as a result of decades of low birth rates (Yung, 2009). In order to compensate for the decrease in student numbers and subsequent losses of income, universities and colleges have: (1) entered 
strategic alliances with other institutions of higher education; (2) intensified cooperation with businesses; (3) closed unprofitable departments; (4) diversified course programs in order to attract different segments of society; (5) lowered student requirements; (6) made staff redundant; (7) cut down on benefits and payments offered to academic personnel. The negative consequences are manifold and include grade inflation (Yung, 2009), an increasing prevalence of academic dishonesty, such as plagiarism and falsification of documents (Lin and Wen, 2007), unprecedented psychological pressure on academic personnel (Yung, 2009: 12), and unethical practices of university management to manipulate performance indicators in order to increase profits. ${ }^{1}$

Although most of the issues have been publicly addressed and have been subjects of various blogs and discussion forums, legislative initiatives to improve the working conditions of academic personnel in higher education have hitherto been limited. It was only in 2010 that the government, after persistent criticism from human rights groups and labor activists, lifted the ban on the formation of teachers' unions (Ting, 2011; Shyu, 2003). Since then, numerous unions have been established in cities around the country, but their bargaining power still remains limited. Teachers' unions, for example, are not allowed to call for a strike (Tsai, 2011). A further obstacle appears to be that union leaders lack legal and organizational expertise to operate their unions effectively. ${ }^{2}$

\section{Working conditions and abusive behavior}

As shown in international studies, organizational changes due to increased competition generally lead to intimidating, offensive, degrading or humiliating behavior at the workplace, and seriously worsening the working conditions of employees (Zapf and Einarsen, 2001). Such hostile abusive behavior is commonly referred to as bullying or mobbing and is much in evidence in revitalized higher educational systems around the world (Keashly and Neuman, 2004; Westhues, 2004; Tigrel and Kokalan, 2009; Buka and Karaj, 2012).

What has been revealed as a group form of abusive behavior has been labeled as mobbing. This is as an act of systematic and indiscriminate collective hostility against a specific target for elimination from a workplace organization through non-violent yet malicious and aggressive means through humiliation, devaluation, discrediting and degradation that is often initiated by an individual occupying a position of power or influence (Duffy and Sperry, 2012: 25-27, 50, 52, 55-56, 263; Davenport, Schwartz and Elliott, 1999: 34; Westhues, 2002: 32). This type of hostile conduct in the workplace is instigated by group of perpetrators who attack a single of multiple targeted victims while acting under the auspices of an organizational domain from which the perpetrators' authority is derived. Hostile behavior in the workplace has also been examined as bullying or harassment, by which a wide range of different types of negative acts in the form of individual behaviors that threaten or intimidate one of more individuals, or undermine their reputation or performance. In all such cases, the targeted individuals are repeatedly subject to and experience negative actions and aggressive conduct. The distinguishing factor between them is how mobbing entails the involvement of an organization, while this is lacking in bullying (Duffy and Sperry, 2012: 43, 48).

Actions that substantiate non-physical psychological aggression take place in many forms, whether they are in verbal or written form, such as gossip about negative characterizations regarding an employee's personality, personal life or job performance, and spreading rumors of false information and malicious lies with the intention of attacking a targeted individual's personal or academic credibility. The specific purpose of mobbing is to cast the targeted individuals 
into a negative light to ultimately remove them from the organization, or at least neutralize their influence within it (Duffy and Sperry, 2012: 58, 74, 216, 263-264). Others examples of abusive behavior include: blocking of appointments, blocking of promotions, blacklisting, being criticized harshly and attacked verbally in private or public, being put down in front of others, lied to or deceived, subject to false accusations, attempts made to turn others against the target (Keashly and Jagatic, 2003: 37; Gumbus and Christian, 2010: 220), demeaning someone by setting them up to fail, exclusion, unfair treatment, threatening someone's job security without valid reasons, and deliberately undermining a subordinate with constant criticism. ${ }^{3}$

These types of hostile conduct can occur vertically, whereby supervisors or administrators abuse or misuse power by staging harassment against a subordinate in the workplace hierarchy, when superiors act in a hostile manner by using their authority to intimidate subordinates, or horizontally when it is instigated by employees at the same level in the organization who enlist others to join in the mobbing (Duffy and Sperry, 2012: 102-103; Davenport, Schwartz and Elliott, 1999: 48) of a targeted individual once the process has begun. Bullying of academics can otherwise be instigated by administrators, colleagues or students (McKay, Fratzl and Thomas, 2008: 77). This premeditated hostile conduct is also undertaken with little risk for the consequences of their actions (Lester, 2009: 449), while the victims may not complain for fear of the possibility of retaliation or be unaware of the legal recourses that may be available in their jurisdiction.

Another mobbing tactic has been termed "'puppet master"” bullying. In these cases, the main aggressor enlists others to launch an attack against a targeted victim while placing the responsibility for the instigated action on another party, which may be more common than other forms of mobbing. ${ }^{4}$ The aggressor in such instances may be a peer of the victim who had induced an individual in a superior position of authority to take this form of action, while themselves remaining invisible behind this type of "human shield," and thereby be absolved of facing the consequences of any retaliatory action that the victim may attempt in the interest of self-defense against unjustifiable aggression. This could be particularly significant if the mobbing actions may be construed as being illegal, depending on the jurisdiction in which the mobbing takes place, such as spreading rumors about the victim or insulting them in a public setting, which are criminal violations against specific articles in the Taiwan criminal code that compose the "social conduct law."

\section{Research on workplace bullying}

Early work on mobbing and bullying as two related yet distinct terms referring to specific ways in which eliminative impulses manifest themselves in the workplace (Westhues, 2005: 39), began in the 1960s and 1970s, before further studies demonstrated how these types of hostile conduct manifested themselves in workplaces as collective or individual acts of aggression. Research has indicated that hostile conduct in the workplace transcends geographic boundaries and is prevalent in different types of workplaces. New findings have begun to indicate that workplace harassment in academic settings parallels those in other types of workplaces and in different countries worldwide.

Pioneering research by Heinz Leymann established the foundation for further study of mobbing. There has since been a worldwide interest in this subject that has led to a considerable amount of theoretical and research literature. Konrad Lorenz first introduced the term "mobbing" to describe organizational behavior in a 1968 study on aggression. These were followed by fur- 
ther studies on mobbing by Peter-Paul Heinemann in 1972 and Dan Olweus in 1973. In 1976, Carroll Brodsky published a landmark work on defining harassment in the workplace. Heinz Leymann later introduced pioneering work on workplace mobbing to describe abusive workplace behavior in various works (Leymann, 1986, 1990, 1993, 1996). These led to worldwide interest in this inadequately understood phenomenon relating to offences against the preservation of basic human dignity. Leymann outlined a process for the elimination of a target in the workplace with the sanction of the administration or management. Dieter Zapf (1996, 1999, 2001, 2003) and others followed Leymann's earlier research on mobbing with the term bullying to describe new research on workplace abuse. Leymann's work was followed by Davenport, Schwartz, and Elliott in the first work on workplace mobbing in the US in 1998, which was followed by Helge Hoel, Charlotte Rayner and Cary L. Cooper comprehensively reviewing and analyzing the literature by that time (Hoel, Rayner and Cooper, 1999). Also during this time and thereafter, Kenneth Westhues $(1998,2004,2005,2006,2008)$ also followed Leymann's research in its qualitative application in the specific sphere of academic workplaces through presenting various case studies.

Bjorkqvist, Österman, and Hjelt-Bäck (1994) published the first examination of workplace harassment in higher education. Keashly's study in cooperation with Joel H. Neuman (2010) on bullying in higher education in particular synthesizes the literature on bullying in the academic sphere and offers an analysis, which complements the earlier studies by Westhues. Other studies (Bjorkqvist, 1994; Rayner, 1997; Lester, 2009) have examined instances of workplace bullying in higher education in the contexts of particular institutions, while Lewis (1999) has examined bullying among higher education academic community in Wales. A detailed examination of academic bullying is also examined in Faculty Incivility (Twale and De Luca, 2008). Tigrel and Kokalan (2009) used qualitative and quantitative methods to investigate mobbing in Turkish institutions of higher education. In a more recent study, Buka and Karaj (2012) looked at workplace harassment at Albanian universities in a nationwide survey.

\section{Research on workplace bullying in Taiwan and the role of THEFS}

The concept of bullying is publicly known in Taiwan and there is only one Chinese term, baling, in usage to describe this phenomenon. Taiwan differs significantly in this respect from South Korea, another highly-developed East Asian democracy, where bullying as defined in European and North American literature lacks an equivalent term, and thus has to rely on descriptions employing a series of related terms (Seo 2010). Most Taiwanese have become familiar with baling during their high school years, and bullying at school has been a publicly acknowledged phenomenon for several decades. Studies on bullying carried out by local scholars, such as Chen and Astor (2009), Wei et al (2007, 2010), and Huang and Chou (2010), have thus primarily focused on bullying in schools. Bullying as a form of workplace harassment has not been researched in as much depth.

In recent years however, there has been an increase in theoretical studies on workplace bullying. For example, Ma, Wang and Chen (2011) have examined the various definitions of bullying and common survey methodologies to measure the prevalence of bullying. Hong and Wang (2008) investigated the relationship between intra-personal conflicts and bullying. A further set of studies compares workplace bullying in Taiwan with other countries, such as Tian (2012), who examines the differences and commonalities of workplace harassment in Japan and Taiwan from a legal perspective. In another study, Tai (2010) investigates the measures for preventing,

86 | Journal of Contemporary Eastern Asia, Volume 12, No.1 
controlling and redeeming of workplace violence in the US, Canada, UK and Australia, and points out deficiencies in the current legal framework in Taiwan to address this issue. Research articles published in international journals remain scarce and seem to be limited to bullying of nurses in hospitals (Chen et al, 2009; Chen et al, 2008). Surveys on the prevalence of workplace bullying have hitherto only been conducted by non-academic institutions, such as the Labor Affairs Council, a government agency, and by 1111 Renli Yinhang, a leading online job agency. These online surveys have consistently shown that more than half of the people interviewed were exposed to bullying. The most common form of workplace bullying are verbal attacks (54 percent), followed by abuse in relationships, such as being overruled, ignored, sidelined or ostracized by colleagues or superiors (26 percent). About 15 percent experienced work-related bullying, such as being given unrealistic goals and deadlines. Another 4 percent were exposed to psychological terror and less than 1 percent to physical abuse. ${ }^{5}$

However, the issue of bullying in higher education has been neglected by scholars as well as labor activists and government institutions, despite increasing numbers of reports of worsening working conditions and conflicts between university management and academic personnel. The Taiwan Higher Education Faculty Survey attempts to shed light on latter developments in Taiwan and its findings should contribute to clarify the impact globalized educational reforms have had on working conditions in the sphere of higher education in Taiwan.

\section{Applied methodology of THEFS}

THEFS is an online survey aiming at obtaining concrete evidence on how working conditions of faculty members at institutions of higher education in Taiwan have related to the impact of recent reforms in the educational sectors on the livelihood of teaching professionals, how they deal with such changes, and thereby evaluate the research findings. Particular focus is given to quantifying the prevalence of bullying.

\section{Participants}

The survey targets a total of 65,000 educators employed in institutions of higher education in Taiwan. Invitations are distributed through labor unions and similar institutions, with a short text describing the aims and procedure of the study as well as assuring the potential respondents that the survey is anonymous and that no individual would be identified in analyzing and reporting the data. In order to increase the number of respondents, snowball sampling is also applied. The English version was translated into Mandarin Chinese and modified using plain Mandarin Chinese language expressions by one of the authors and a bilingual researcher. A team of professional translators back-translated the instrument into English, and then compared it with the original English version to verify the accuracy of the translation. No discrepancies were found between the two language versions. In addition, the Mandarin Chinese translation was tested with a group of eight university teachers to receive their feedback. No revision was necessary.

\section{Measurements}

Since the early 1990s, a number of different methodologies have been applied to measure workplace bullying. Questionnaires have been the predominant method used in most large-scale surveys (Cowie et al, 2002: 38). In recent studies that were carried out in Europe and the USA, the

April/May 2013 | 87 
prevalence of workplace bullying was measured by applying the so-called subjective survey method, which provides respondents with an exact definition of the concept of bullying and asks for a personal assessment of perceived exposure to bullying at work (Giorgi, 2008: 71). In other studies, surveys employ a list of negative and potentially harassing acts to measure bullying without usually offering a definition thereof to the participants. Most studies of the latter type base on either the Leymann Inventory of Psychological Terror (LIPT) or the Negative Acts Questionnaire (NAQ). The LIPT comprises 45 categories of acts of bullying and serves as diagnostic tool to identify victims of severe bullying likely to be traumatized from their experiences (Staale Einarsen, Hoel and Notelaers, 2009: 25). The NAQ was developed by Einarsen and Raknes (1997) in the late 1990s and was derived from literature studies and accounts given by victims of long lasting harassment (Cowie et al 2002, 39). It consists of 22 items and is a survey instrument rather than a diagnostic tool (Staale Einarsen, Hoel and Notelaers 2009, 25). Einarsen, Hoel and Notelaers (2009) provided considerable evidence of the construct validity of NAQ-R by demonstrating dimensionality, validity and internal consistency (Giorgi, 2008: 73). With a total of 22 short and easy-to-read items, the NAQ-R has become increasingly popular among researchers of workplace bullying in recent years. It has been translated into a number of languages and successfully tested in studies conducted in various parts of the world. In this survey, NAQ-R is used to measure incidents of bullying. All of the items in the NAQ-R are described without reference to the word "bullying" or "harassment." Respondents are asked to indicate the frequency of exposure to negative acts within the past 6 months, with response alternatives: "Never," "Now and then," "Monthly," "Weekly," and "Daily." A single-item measuring self-labeled victimization from bullying during the last six months is included after presenting the respondents with the following definition of bullying (Tsuno et al, 2010: 218): "We define bullying as a situation where one or several individuals persistently over a period of time perceive themselves to be on the receiving end of negative acts from one or several persons, in a situation where the target of bullying has difficulty in defending him or herself against these acts. We will not refer to a one-off incident as bullying." Response categories are identical with the NAQ-R items. Those who consider themselves as having been exposed to bullying are categorized as self-labeling victims of workplace bullying (Ståle Einarsen and Skogstad, 1996) and are asked what approaches they have considered taking or have actually taken to cope with the bullying.

\section{Other measures}

Mental and psychosomatic health. Mental health is measured by the 12-item version of General Health Questionnaire GHQ-12. The questionnaire was developed by Goldberg (1978) to quantify the risk of developing psychiatric disorders by assessing the respondent's inability to carry out normal functions and the appearance of distress (Goldberg, 1978). The validity of the GHQ-12 has been confirmed in several studies (Goldberg and Blackwell, 1970; Goldberg et al, 1997). Psychosomatic health complaints are measured by using a 12-item scale taken from the Occupational Stress Indicator (OSI). The OSI was developed by Cooper and Williams (1988) and designed to measure the key components of the stress process-effects, sources and individual differences (Williams and Cooper, 1998). The reliability and validity of the psychosomatic health scales has been tested extensively and confirmed in various studies (Williams and Cooper, 1998: 308; Robertson et al, 1990). 
Psychosocial and environment quality. Three subscales from the Pressure Management Indicator (Williams and Cooper, 1998), a revised version of the OSI, are employed: "Relationships with Colleagues" includes two items measuring the support and interaction with colleagues; "Organizational climate" includes 14 items focusing on the atmosphere and working conditions; while "Organizational satisfaction" includes five items measuring the respondent's level of satisfaction with the job itself and the organization. Two further subscales are added: "Organizational changes" include nine items measuring the occurrence of significant changes in respondent's working environment; "Level of adaption" include four items focusing on the likelihood of possible responses to the changing working environment.

\section{Expected outcomes}

As was indicated in the previous sections, organizational changes due to increased competition generally lead to intimidating, offensive, degrading or humiliating behavior at the workplace, seriously worsening the working conditions of employees. Such hostile abusive behavior is commonly referred to as bullying or mobbing and much in evidence in revitalized higher educational systems around the world.

The liberalization of higher education in Taiwan and decades of unprecedented low birth rates have forced universities and colleges in Taiwan to reduce personnel, to increase the workload of teaching faculty and to minimize fringe benefits, and thereby significantly worsening working conditions and intensifying competition. The survey is thus expected to show increasing prevalence of workplace bullying. In addition, the survey may confirm other comparative studies, such as Power et al (2013), which have shown comparatively high acceptance levels of workplace bullying among employees in Taiwan due to cultural factors.

The findings of the survey are expected to assist the scientific community in carrying out further comparative studies on workplace bullying, and how victims have coped with its effects. It should also assist policy makers in formulating organizational and legislative strategies to prevent workplace bullying in higher education in the future.

\section{Notes}

${ }^{1} \mathrm{http}: / /$ bulliedacademics.blogspot.tw/2013/06/taiwan-university-administration.html

${ }^{2}$ Interview, union activists, Taichung, April 2013.

${ }^{3} \mathrm{http}: / /$ www.acas.org.uk/CHttpHandler.ashx?id=306\&p=0.

${ }^{4} \mathrm{http} / / /$ newworkplace.wordpress.com/2012/01/23/puppet-master-bullying-vs-genuine-mobbing-at-work/

${ }^{5}$ http://www.cna.com.tw/News/FirstNews/201210310042-1.aspx;

http://hr.1111.com.tw/knowledgeDetail.asp?kind=1\&lno=986

\section{References}

Altbach, Philip G. and Jane Knight. 2007. "The internationalization of higher education: Motivations and realities." Journal of Studies in International Education 11 (3-4): 290-305.

Armbruster, Chris. 2008. "Research Universities: autonomy and self-reliance after the Entrepreneurial University." Policy Futures in Education 6 (4). 
Barber, Michael, Katelyn Donnelly, Saad Rizvi, Lawrence Summers. 2013. An avalanche is coming: higher education and the revolution ahead. London: Institute for Public Policy Research.

Beasley, W. G. 1987. Japanese imperialism, 1894-1945. Oxford, Oxfordshire: Clarendon Press. Bjorkqvist, Kaj, Karin Österman and Monica Hjelt-Bäck. 1994. "Aggression among university employees.” Aggressive Behavior 20: 173-184.

Brodsky, Carroll. 1976. The Harassed Worker. Lexington, MA: Lexington Books.

Buka, M. S. M. and T. Karaj. 2012. "Mobbing in the Academe: The Case of Albanian Universities" in Proceedings of the 2nd International Conference on Human and Social Sciences (Vol.8) edited by A. Biagini et al. Rome: Mediterranean Center of Social and Educational Research: 26-29. Doi:10.5901/ichss-2012-vol-08

Chen, Ji-Kang and Ron Avi Astor. 2009. "The Perpetration of School Violence in Taiwan An Analysis of Gender, Grade Level and School Type." School Psychology International 30 (6): 568-584.

Chen, Wen-Ching et al. 2008. "Prevalence and Determinants of Workplace Violence of Health Care Workers in a Psychiatric Hospital in Taiwan". Journal of Occupational Health 50 (3): 288-293.

Chen, Wen-Ching et al. 2009. "Incidence and Risk Factors of Workplace Violence on Nursing Staffs Caring for Chronic Psychiatric Patients in Taiwan”. International Journal of Environmental Research and Public Health 6 (11): 2812-2821. doi:10.3390/ijerph6112812.

Clark, Burton R. 1998. Creating Entrepreneurial Universities: Organizational Pathways of Transformation. Issues in Higher Education. New York: Elsevier.

Cook, Tim et al. 2008. "Commercializing University Research: Threats and Opportunities-The Oxford Model". Capitalism and Society 3 (1).

Cowie, Helen et al. 2002. "Measuring workplace bullying". Aggression and Violent Behavior 7 (1): 33-51. doi:10.1016/S1359-1789(00)00034-3.

Davenport, Noa, Ruth Distler Schwartz and Gail Pursell Elliott. 1999. Mobbing: Emotional abuse in the American workplace. Civil Society Pub.

Deem, R., K. H. Mok and L. Lucas. 2008. "Transforming higher education in whose image? Exploring the concept of the "world-class' university in Europe and Asia". Higher education policy 21 (1): 83-97.

Dobbins, Michael, Christoph Knill and Eva Maria Vögtle. 2011. "An analytical framework for the cross-country comparison of higher education governance". Higher Education 62 (5): 665-683.

Duffy, Maureen P., Maureen Duffy and Len Sperry. 2012. Mobbing: Causes, Consequences, and Solutions. Oxford: Oxford University Press.

Einarsen, Staale, Helge Hoel and Guy Notelaers. 2009. "Measuring exposure to bullying and harassment at work: Validity, factor structure and psychometric properties of the Negative Acts Questionnaire-Revised". Work \& Stress 23 (1): 24-44. doi:10.1080/02678370902815673.

Einarsen, Ståle and Anders Skogstad. 1996. "Bullying at work: Epidemiological findings in public and private organizations". European Journal of Work and Organizational Psychology 5 (2): 185-201. doi:10.1080/13594329608414854.

Etzkowitz, Henry and Loet Leydesdorff. 2000. "The dynamics of innovation: from National Systems and "Mode 2" to a Triple Helix of university-industry-government relations." $R e$ search Policy 29 (2): 109-123. 
Giorgi, Gabriele. 2008. "The Negative Acts Questionnaire Revised (NAQ-R) in Italia." Prevenzione Oggi 4: 71-82.

Giroux, Henry A. 2002. "Neoliberalism, corporate culture, and the promise of higher education: The university as a democratic public sphere." Harvard Educational Review 72 (4): 425464.

Goldberg, David. 1978. Manual of the general health questionnaire. Windsor, Berks: NFERNelson.

Goldberg, David P. and Barry Blackwell. 1970. "Psychiatric illness in general practice: a detailed study using a new method of case identification." British medical journal 2 (5707): 439.

Goldberg, David P. et al. 1997. "The validity of two versions of the GHQ in the WHO study of mental illness in general health care." Psychological medicine 27 (01): 191-197.

Gumbus, Andra and Valerie L. Christian. 2010. "Grin and Bear It? Jill's Dream or Demise," Journal of Behavioral and Applied Management 11 (2): 205-229.

Hoel, Helge, Charlotte Rayner and Gary L. Cooper. 1999. "Workplace Bullying." International Review of Industrial and Organizational Psychology 14: 195-230.

Hong, Tsan-kai and Wang Chi-yong. 2008. The Effects of Interpersonal Conflicts on the Workplace Bullying [renji chongtu dui zhichang baling xingwei yingxiang zhi tantao]. Paper presented at the 2008 Conference on Chinese Business Competitiveness and Operational Management. Hsinchu: Chung Hua University.

Huang, Yun-yin and Chien Chou. 2010. "An analysis of multiple factors of cyberbullying among junior high school students in Taiwan." Computers in Human Behavior 26 (6): 15811590.

Keashly, Loraleigh and Karen Jagatic. 2003, "By any other name: American perspectives on workplace bullying" in Bullying and emotional abuse in the workplace: International perspectives in research and practice edited by Ståle Einarsen, Helge Hoel, Dieter Zapf and Cary Cooper. London: Taylor Francis.

Keashly, Loreleigh. \& Joel H. Neuman. 2004. "Bullying in the workplace: Its impact and management." Employee Rights and Employment Policy Journal. 8(2): 335-373.

Kwiek, Marek. 2008. "Academic entrepreneurship vs. changing governance and institutional management structures at European universities." Policy futures in Education 6 (6): 757 770 .

Lester, Jaime. 2009. "Not Your Child's Playground: Workplace Bullying Among Community College Faculty." Community College Journal of Research and Practice, 33 (5): 444462.

Lewis, Duncan. 1999. "Workplace bullying: interim findings of a study in further and higher education in Wales." International journal of manpower: international manpower forecasting, planning and labour economics. 20 (1/2): 107-118.

Lin, Chun-Hua Susan and Ling-Yu Melody Wen. 2007. "Academic Dishonesty in Higher Education-a Nationwide Study in Taiwan." Higher Education 54 (1): 85-97. doi:10.1007/s10734-006-9047-z.

Liu, Nian Cai, and Ying Cheng. 2005. "The academic ranking of world universities." Higher education in Europe 30 (2): 127-136.

Ma, Shu-ching, Wang Hsiu-hung and Chen Jih-yuan 2011. "Concept Analysis of Workplace Bullying" [zhichang baling de gainian fenxi], Journal of Nursing 58 (4): 81-86. 
Mainardes, Emerson Wagner, Helena Alves and Mario Raposo. 2011. "The process of change in university management: From the 'Ivory Tower' to 'Entrepreneurialism'." Transylvanian Review of Administrative Sciences 33 (2): 124-149.

McKay, Arnold R., D. H. Fratzl and J. Thomas, R. 2008 "Workplace Bullying In Academia: A Canadian Study." Employee Responsibilities and Rights Journal 20 (2): 77-100.

Mok, K. H. 2003. "Globalisation and higher education restructuring in Hong Kong, Taiwan and Mainland China." Higher Education Research and Development 22 (2): 117-129.

Page, Stephen. 2005. "What's New About the New Public Management? Administrative Change in the Human Services." Public Administration Review 65 (6): 713-727. doi:10.1111/j.1540-6210.2005.00500.x.

Phillips, Steven E. 2003. Between assimilation and independence: the Taiwanese encounter nationalist China, 1945-1950. Stanford, Calif: Stanford University Press.

Power, Jacqueline L. et al. 2013. "Acceptability of workplace bullying: A comparative study on six continents." Journal of Business Research 66 (3): 374-380. doi:10.1016/j.jbusres.2011.08.018.

Rayner, Carroll. 1997. "The incidence of workplace bullying." Journal of Community and Applied Social Psychology 7(3): 199-208.

Readings, B. 1996. The University in Ruins. Cambridge, MA: Harvard Business School Press.

Ritzer, G. 1996. "McUniversity in the Postmodern Consumer Society." Quality in Higher Education 2 (3): 185-199.

Robertson, Ivan T., Cary L. Cooper, Janet Williams and Janet Williams. 1990. "The validity of the occupational stress indicator". Work \& Stress 4 (1): 29-39.

Sbragia, Alberta M. 2000. "Governance, the State, and the Market: What Is Going On?" Governance 13 (2): 243-250. doi:10.1111/0952-1895.00132.

Seo, Yoojeong Nadine. 2010. "The role of culture on workplace bullying: the comparison between the UK and South Korea". PhD thesis. Nottingham: University of Nottingham.

Shattock, Michael. 2008. Entrepreneurialism in Universities and the Knowledge Economy: Diversification and Organisational Change in European Higher Education. Berkshire: Open University Press.

Shyu, Tin-yei. 2003. Research on Teacher's Union in Taiwan-Discussion from the View of Political Society [wo guo jiaoshi chouzu gonghui zhi yanjiu: zhengzhi shehui jiaodu de tantai]. MA thesis. Chiayi: Nanhua University.

Suzuki, D. 1989. The Prostitution of Academia: Inventing the Future, Reflections on Science, Technology and Nature. Melbourne: Allen \& Unwin.

Tai, Sheng Yu. 2010. Comparative Study of the Issues and Prevention Measures on Workplace Violence [zhichang baoli wenti yu fangzhi cuoshi zhi bijiao yanjiu]. MA thesis. Taipei: National Chengchi University.Tian Ya-hsin. 2012. Comparative Legal Study on Workplace Bullying Between Taiwan and Japan [taiwan yu riben zhichang baling zhi bijiaofa yanjiu]. MA thesis. Taipei: National Taiwan University.

Tigrel, E. Yelgecen, and O. Kokalan. 2009. "Academic mobbing in Turkey." International Journal of Behavioral, Cognitive, Educational and Psychological Sciences 1 (2): 91-99.

Ting, Hui-hsiang. 2011. The Development of Teachers' Labor Rights In Taiwan, 1949-2011 [wo guo jiaoshi laodongquan fazhan zhi yanjiu]. MA thesis. Taipei: National Taiwan University.

92 | Journal of Contemporary Eastern Asia, Volume 12, No.1 
Tsai, Chin-tian. 2011. "Challenges and Compliances: Taiwan Teachers' Union from an Organizational Perspective" [cong jiaoshi zhuzhi fazhan tanjiu woguo jiaoshi gonghui de tiaozhan yu yinying] Jiиуи Yanjiu 203: 28-39.

Tsuno, K., N. Kawakami, A. Inoue and K. Abe. 2010. "Measuring workplace bullying: Reliability and validity of the Japanese version of the Negative Acts Questionnaire." Journal of occupational health 52 (4): 216-226.

Twale, Darla J. and Barbara M. De Luca. 2008. Faculty Incivility: The Rise of the Academic Bully and What to Do About it. San Francisco: Jossey-Bass.

Varghese, N. V. 2012. "Higher Education Reforms and Revitalization oi the Sector". Higher Education Forum 9: 45-59.

Wang, R. J. 2003. "From elitism to mass higher education in Taiwan: The problems faced." Higher Education 46 (3): 261-287.

Wei, Hsi-sheng, Melissa Jonson-Reid and Hui-ling Tsao. 2007. "Bullying and victimization among Taiwanese 7th graders: A multi-method assessment." School Psychology International 28 (4): 479-500.

Wei, Hsi-Sheng, James Herbert Williams, Ji-Kang Chen and Hsiu-Yu Chang. 2010. "The effects of individual characteristics, teacher practice, and school organizational factors on students' bullying: A multilevel analysis of public middle schools in Taiwan." Children and Youth Services Review 32 (1): 137-143.

Westhues, Kenneth. 2002. "At the mercy of the mob," Occupational Health \& Safety Magazine Canada 18 (8): 30-36.

Westhues, Kenneth ed. 2004. Workplace Mobbing in Academe: Reports from Twenty Universities. Queenston: Edwin Mellen Press.

Westhues, Kenneth. 2005. The Envy of Excellence: Administrative Mobbing of High-Achieving Professors. Queenston: Edwin Mellen Press.

Wilkesmann, Uwe and Christian J. Schmid. 2012. "The Impacts of New Governance on Teaching at German Universities. Findings from a National Survey." Higher Education 63 (1): 33-52. doi:10.1007/s10734-011-9423-1.

Williams, S and C L Cooper. 1998. "Measuring occupational stress: development of the pressure management indicator." Journal of occupational health psychology 3 (4): 306-321.

Wu, Wen-Hsing, Shun-Fen Chen and Chen-Tsou Wu. 1989. "The Development of Higher Education in Taiwan." Higher Education 18 (1): 117-136. doi:10.1007/BF00138963.

Yung, Chaur-Shin. 2009. "Taiwan Higher Education and the Challenges for the Good and the Excellence" [taiwan gaodeng jiaoyu de tiaozhan, chaoyue yu zhuoyue] Jiaoyu Ziliao Jikan 44: 1-28.

Zapf, Dieter and Ståle Einarsen. 2001. "Bullying in the workplace: recent trends in research and practice - an introduction." European Journal of Work and Organizational Psychology 10(4): 369-373.

Zapf, Dieter. 1999. "Organizational, work group related and personal causes of mobbing/bullying at work." International Journal of Manpower 20 (1) 